\title{
CONTINUOUS DISSOLVER THEORY \\ III. Development of General Tank-Flow Relationships with Application to Pilot Plant Data for a \\ Flooded Column Dissolver
}

\author{
by

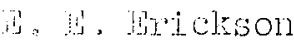

Chemical Development Section

CPP Technical Branch

Previous Reports in This Series

IDO-14450 CONTINUOUS DISSOLVER THEORY

I. Development of General Relationships

for a Tube-Flow Flooded Dissolver

IDO-14451 CONTINUOUS DISSOLVER THEORY

II: Application of Thbe-Flow Dissolver Theory

to Data from a 2 -Inch, Continuous

Flooded Dissolver

Repori Written

September 15, 1958

This document is

MUBLICLY RELEASABLIS

BSteelo

Authorizing Official

Date: $\quad 3 / 22 / 06$

\section{PHILLIPS PETROLEUM COMPANY \\ Atomic Energy Division $\operatorname{AT}(10-1)-205$}

IDAHO OPERATIONS OFFICE

U. S. ATOMIC ENERGY COMMISSION 


\section{DISCLAIMER}

This report was prepared as an account of work sponsored by an agency of the United States Government. Neither the United States Government nor any agency Thereof, nor any of their employees, makes any warranty, express or implied, or assumes any legal liability or responsibility for the accuracy, completeness, or usefulness of any information, apparatus, product, or process disclosed, or represents that its use would not infringe privately owned rights. Reference herein to any specific commercial product, process, or service by trade name, trademark, manufacturer, or otherwise does not necessarily constitute or imply its endorsement, recommendation, or favoring by the United States Government or any agency thereof. The views and opinions of authors expressed herein do not necessarily state or reflect those of the United States Government or any agency thereof. 


\section{DISCLAIMER}

Portions of this document may be illegible in electronic image products. Images are produced from the best available original document. 
IDO-14452

Page 4

\section{CONTINUOUS DISSOLVER THEORY}

III. Development of General Tank-Flow Relationships with Application to Pilot Plant Data for a

Flooded Column Dissolver

by

E. E. Erickson

$\underline{A} \underset{-}{S} \underline{T} \underset{-}{A} \underline{T}$

General relationships are developed for the performance of continuous flooded dissolvers based on complete mixing; i.e., tank flow, uniform packing characteristics of metal, and a first-order rate law. The form of the final equation is the same as that derived for the nonmixing or tube-flow case discussed in earlier reports of this series, with differences appearing only in the term that expresses the concentrations of metal and dissolvent in the liquid phase.

The relationships are applied to available pilot plant data on the mercury-catalyzed dissolution of four shapes of $2 S$ aluminum elements. The data cover a range of catalyst concentrations from $1.5 \times 10^{-6}$ to $3.75 \times 10^{-4}$ molar $\mathrm{Hg}^{++}$and metal bed heights from 1 to 10 feet in a 2 -inch pyrex column. The average initial dissolvent concentration was 5.6M nitric acid. Round rods, flat plates, tubes, and flattened tubes are compared. The data for the round rods are utilized to determine the effective reaction velocity constants at the various catalyst concentrations. The general dissolver equation is used to predict the effect on dissolution rate of the shape of metal elements, liquid phase flow rate, and height of the bed of elements. Calculated rates follow the trends in the data, but not quite so well as calculated rates for the nonmixing or tube-flow case. The mathematical representation of the model is generally consistent with the pilot plant data. 
Page No.

1. SUMMARY - - - - - - - - - - - - 7

2. INTRODUCTION - . . . . . . . . . . . . 8

3. DERIVATION OF EQUATIONS - - - - . - . - . - 9

3.1 The Model - _ _ _ . . . . . . . . - 9

3.2 General Relationships Required - . - . - . - - 10

3.3 Treatment of Specific Ideal Shapes - . - . - - 14

3.31 One-Dimensional Attack - . . . . . . . - 14

3.32 Two-Dimensional Attack- - - - - - - - - 15

3.33 Three-Dimensional Attack - . . . . . . - 16

3.4 Summary of Relationships _ . . . . . . . . 16

4. APPLICATION OF MODEL TO PILOT PLANT DATA - - - - - - - 17

4.I Method of Calculation- _ . . . . . . . . - 17

4.2 Prediction of Dissolution Rates- - - - . - - - 23

4.21 Effect of Shape of Element- - - - - - - - 23

4.22 Effect of Column Height - . - . - . - - 23

5. DISCUSSION- - . . . . . . . . . . . 30

6. NOMENCLATURE- . . . . . . . . . . . . . 32

7. REFERENCES- - _ . . . . . . . . . . - 34 
IDO-14.452

Page 6

\section{LIST OF FIGURES}

Figure No.

Title

Page No.

1 Evaluation of the Function of Concentration - - - - 19

2 Effective Specific Reaction Velocities for Round

Aluminum Rods _................... 21

3a Predicted Aluminum Dissolution Rate Curves

for Catalyst Concentration $=7.5 \times 10^{-4} \mathrm{M}-\ldots$

3b Predicted Aluminum Dissolution Rate Curves

for Catalyst Concentration $=3.75 \times 10^{-4} \mathrm{M}-\cdots 25$

3c Predicted Aluminum Dissolution Rate Curves

for Catalyst Concentration $=7.5 \times 10^{-5} \mathrm{M}-\ldots . . .-26$

$3 d$ Predicted Aluminum Dissolution Rate Curves

for Catalyst Concentration $=1.5 \times 10^{-5}$ M- . - . - 27

3e Predicted Aluminum Dissolution Rate Curves

for Catalyst Concentration $=1.5 \times 10^{-6} \mathrm{M}_{-} \ldots \ldots$

4 Effect of Bed Height on Dissolution Rate- - - - - - 29

\section{LIST OF TABLES}

Table No.

Title

Page No.

1 Constants for the Dissolver Equation- . - . - - 18

2 Calculated Effective Specific Reaction Velocities

for Round Rods- . . . . . . . . . . . . . . 22

3 Predicted Dissolution Rates for Four Shapes

of Aluminum Elements - . . . . . . . . . - 23

4 Effect of Bed Height on Dissolution Rate- . . . - . 30 


\title{
CONTINUOUS DISSOLVER THEORY
}

\author{
III. Development of General Tank-Flow Relationships \\ with Application to Pilot Plant Data for a \\ Flooded Column Dissolver \\ by
}

E. E. Erickson

1. SUMMARY

General relationships for the performance of a continuous flooded dissolution column are developed for the tank-flow case; $i . e .$, the case in which mixing is assumed to be complete and instantaneous. A general dissolver equation is obtained from a first-order rate law that is of the same form as that derived previously(3) for the nonmixing or "tubeflow" case in which first-order and parabolic rate laws were assumed. All of the differences appear in a single term of the equation, $\theta(C)$, a function of the concentration, which can be derived quite readily for various cases of interest.

The dissolver equation, used with physical constants and specific reaction velocities obtained from the data of Boeglin and Buckham(I), predicts nearly the same dissolution rates as does the equation for the nonmixing case in spite of the difference in the $\theta(C)$ term. Differences in reaction velocity constants calculated from the dissolver equation are compensating. The trends in dissolution rates with dissolvent flow rate and shape of fuel element for $1 / 4$-inch round rods, 5/8-inch tubes, 5/16-inch thick plates, and flattened 5/8-inch tubes of extruded $2 \mathrm{~S}$ aluminum indicated by the equation match the data trends nearly as well as do trends indicated by tube-flow equation $(4)$. While the tube flow and tank flow situations represent the two limiting conditions for operation of a flooded dissolver, the actual flow conditions appear to lie somewhere between these two ideal cases.

The general dissolver equation may be expressed as the product of dimensionless groups as follows:

$$
\frac{H}{\bar{D}}=\frac{p}{2 F K} \quad[\theta(c)]\left[\frac{a_{0}}{D}\right] \quad\left[\frac{S^{\prime}}{k}\right]
$$

where

$$
\begin{aligned}
& H=\text { height of bed of metal elements } \\
& D=\text { column diameter } \\
& p=\text { element shape factor, dimensionless }
\end{aligned}
$$


$F=$ gas evolution factor, dimensionless

$K=$ pscking factor, dimensionless

$\theta(C)=$ a dimensionless function of concentration

$=\frac{2 C_{p}}{B-L p}$ for the case in question

$\mathrm{C}_{p}=$ concentration of metal in product

$B=$ initial concentration of dissolvent

$I$ = stoichiometric ratio for reaction, dimensionless

$a_{0}=$ minimum length dimension of initial element

$S^{\prime}=$ superficial liquid velocity

$k=$ specific reaction velocity

The dimensions used for the above terms must be consistent with the general equation.

The use of this equation for either the nonmixing or the complete mixing case permits prediction of trends in dissolution rates that are reasonably consistent with the data; when the constants are evaluated, quantj.tative estimates of dissolution rates can be made. Since the relatiorships developed are intended mainly as the demonstration of an approach to the problem, they should be applied only with full consideration of the assumptions upon which the derivations depend. Present knowledge concerning the factors involved and the reaction kinetics must be extended considerably before such relationships can be applied directly to process design.

\section{INTRODUCTION}

Dissolution of spent reactor fuel elements may be carried out in any of several types of equipment. Cne of the most effective, if the fuel elements are of suitable size, is the continuous flooded dissolver. The metal elements are fed in the top of a column intermittently to maintain the level of the metal bed above a predetermined height, and the dissolvent is pumped continuously to the bottom. Dissolvent flows up through the column and the effluent or product overflows at the top.

The continuous flooded dissolver, treated as a continuous countercurrent reactor in which there is no longitudinal mixing, is the subject of the first two reports in this series $(3,4)$. The assumption of nonmixing flow is open to question since gas evolution during dissolution creates violent surging with considerable longitudinal mixing. The real case lies somewhere between the nonmixing or "tube-flow" behavior and the opposite extreme, that of complete and instantaneous mixing or tank...low behavior. This report discusses the tank-flow approach to the flooded dissolution column.

General relationships are developed for the tank-flow situation taking into account the variation in liquid-solid interfacial area over the height of the metal bed. A single dissolver equation in terms of 
dimensionless parameters is derived and the equation applied to available pilot plant data for the mercury-catalyzed dissolution of $2 S$ aluminum in nitric acid. The trends in dissolution rates with variations in acid flow rate, shape of fuel element, and height of metal bed are predicted through the use of the general equation and compared with the trends of rates measured in the pilot plant.

\section{DERIVATION OF EQUATIONS}

\subsection{The Model}

The model chosen is that of a simple acid-dependent first order reaction occuring in a column in which metal fuel elements are being fed continuously at the top and dissolvent fed continuously at the bottom. Mixing of the liquid phase is uniform throughout the column and is assumed to be complete and instantaneous, in that the liquid phase composition is uniform throughout the column and is identical with the composition of the product stream. The rate of reaction, which depends on the liquid-metal interfacial area, varies over the height of the column as the surface area of the metal bed varies. Dissolution is complete with no metal discharging from the bottom of the dissolver. The operation is in steady state.

While a first order rate law is assumed here, the derivation for a different law can be carried out by the same procedure, if desired.

The dissolution rate may be expressed as

$$
-\frac{\mathrm{dm}}{\mathrm{dt}}=\mathrm{k} \mathrm{s}^{\prime} \quad\left[\mathrm{H}^{-7}\right]
$$

where

$$
\begin{aligned}
-\frac{d m}{d t}= & \text { rate of dissolution of metal per unit volume of reactor } \\
& \text { at a given point in the column } \\
d= & \text { specific reaction rate per unit interfacial area per unit } \\
& \text { of acid concentration } \\
s^{\prime}= & \text { surface area of metal per unit volume of reactor at a } \\
& \text { given point in the column } \\
{\left[\mathrm{H}^{-}\right]=} & \text {hydrogen ion concentration in reactor }
\end{aligned}
$$

The rate of reaction can variously be written also as

$$
\begin{aligned}
& r=\frac{M}{V} \\
& r=\frac{S\left(C_{p}-C_{f}\right)}{V} \\
& r=k \operatorname{siv}_{a v}\left[B-L\left(C_{p}-C_{f}\right)\right]
\end{aligned}
$$

where

$$
\begin{aligned}
& r=\text { average reaction rate per unit volume } \\
& M=\text { mass feed rate of metal to column }
\end{aligned}
$$




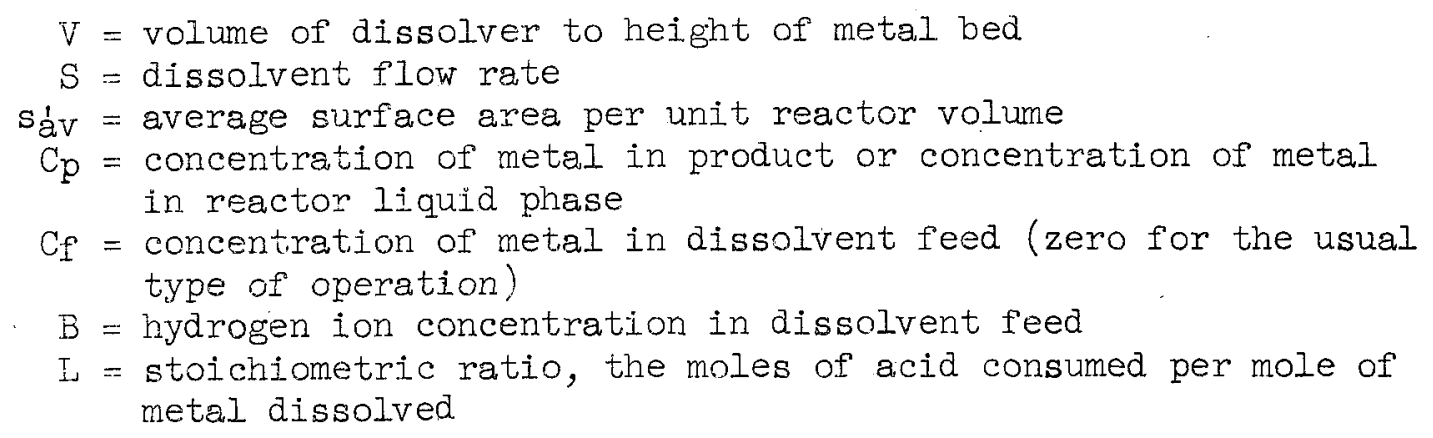

The assumption of constancy of the liquid rate, $S$, is required here. While the liquid volume does change slightly, the major part of which is due to evaporation of water, the change is not great and the assumption appears to be valid. Also, as part of the model, it is recuired that the elements being dissolved are of such a size and shape that they will present uniform bed packing characteristics; $i . e_{\circ}$, the void volume is uniform over the height of the metal bed. For the element shapes that have been studied most often, rods and tubes of length somewhat greater than column diameter and of diameter much smaller than column diameter, this assumption appears to be reasonably valid $(1,5)$. By the volume of the reactor column is meant the volume of the column up to the height of the packed bed of metal elements.

\subsection{Gerieral Relationships Required}

The various forms of the dissolution rate, equations (2-4), may be expressed as

$$
\frac{I M}{V}=\frac{S\left(C_{p}-C_{I}\right)}{V}=k S_{Q v}^{\prime} \quad\left[B-I \cdot\left(C_{p}-C_{f}\right)\right]
$$

from which the total dissolution rate is

$$
M=S\left(C_{p}-C_{f}\right)=k_{s} a_{v} V\left[B-L_{1}\left(C_{p}-C_{f}\right)\right]
$$

The major problem in utilizing the above equations is in expressing the surface area term, since the area varies with the height of the column. The average surface area per unit volume of reactor may be expressed as

$$
s_{a v}^{\prime}=\frac{\int_{0}^{v} s_{d v}^{t}}{v}
$$

But

$$
s^{\prime}=s_{I} n^{\prime}
$$


where

$$
\begin{aligned}
& \mathbf{s}_{1}=\text { surface area of individual element } \\
& n^{\prime}=\text { number of elements per unit volume. }
\end{aligned}
$$

Equation ( $5 b$ ) now may be written as

$$
M=S\left(C_{p}-C_{f}\right)=k\left[B-L\left(C_{p}-C_{f}\right)\right] \quad \int_{0}^{V} s_{\perp} n^{\prime} d V
$$

A general equation for the volume of the metal element is

$$
\mathrm{v}_{1}=4 \text { eabc }
$$

where

$$
\mathrm{e}=\mathrm{a} \text { shape constant }
$$

and $a, b$, and $c$ are the three length dimensions of the element.

Then

$$
n^{\prime}=\frac{K}{4 \text { eabc }}
$$

where

$$
\begin{aligned}
& K= \text { packing factor or fraction of column volume occupied by } \\
& \text { metal }=\text { (l-void fraction). }
\end{aligned}
$$

Also

$$
s_{I}=2 \text { e }[(a+b) c+a b]
$$

Then

$$
s^{\prime}=s: n^{\prime}=\frac{K[(a+b) c+a b]}{2 a b c}
$$

Now equation (8) may be written as

$$
S\left(C_{p}-C_{f}\right)=\frac{K k\left[B-L\left(C_{p}-C_{f}\right)\right]}{2} \int_{0}^{V} \frac{(a+b) c+a b}{a b c} d V
$$

Account should be taken of the fact that gas evolved in the reaction, both gaseous reaction products and water evaporated by the heat of reaction, appears to block some of the metal surface from effective contact with dissolvent. A gas evolution factor, $F$, to reporesent the fraction of the surface area that is in contact with the Iiquid phase, is incorporated in the area term and is treated as a constant. This factor was discussed in greater detail in an earlier report(4). Equation (13), by including $F$ and rearranging, becomes

$$
\frac{2\left(C_{p}-C_{f}\right)}{B-L\left(C_{p}-C_{f}\right)}=\frac{F K K}{S} \int_{0}^{V} \frac{(a+b) c+a b}{a b c} d V
$$


Equation (14a) is general for all shapes provided the proper interpretation is put on the dimensions for hollow shapes: This latter case requires "opening" the shape and treating it as essentially a flat plate. It remains now to express the dimensions, which vary over the column height, in terms suitable for integration.

Since the concentration throughout the reactor is constant, the rate of dissolution at a given point is a linear function of the surface area at that point. Thus, the rate of attack in terms of thickness of the metal layer dissolved is constant over the height of the column. The decrease in each dimension of the elements then is inversely proportional to the column height. At the bottom of the column, the point at which the element disappears, the smallest dimension of the element becomes zero. Assuming uniform dissolution from all surfaces, at the point of complete dissolution all dimensions have decreased by an amount equai to the smallest dimension of the initial element. Since the change in dimensions is linear along the column and dissolution is uniform, the average dimensions of the slugs in the column are

$$
\frac{a_{0}}{2}, b-\frac{a_{0}}{2} \text {, and } c-\frac{a_{0}}{2}
$$

where $a_{0}$ is the smallest dimension of the initial element, and $b_{0}$ and co are the other two initial dimensions.

The relationships for the average dimensions in the column may be shown also in the following manner:

$$
\operatorname{mdv}=\mathrm{SdC}
$$

Since

$$
\begin{aligned}
d c & =0, m d v=0 \\
m & \neq 0, \text { so } \\
a v & =0
\end{aligned}
$$

and

$$
\mathrm{v}=\text { constant }
$$

where

$$
\begin{aligned}
\mathrm{v}= & \text { velocity of metal flow at any point in the column } \\
& \text { and } \\
\mathrm{m}= & \text { mass of metal per unit column height. }
\end{aligned}
$$

By definition of velocity,

$$
\mathrm{v}=\frac{\mathrm{dh}}{\mathrm{dt}}
$$

where dh is the height of the column section through which the metal moves in time dt.

The dissolution rate is

$$
-\frac{d m}{d t}=k s^{\prime}\left[B-L\left(C_{p}-C_{f}\right)\right]=\rho s^{\prime} \frac{d a}{d t} / c
$$


where the last expression represents the mass of the metal layer dissolved. Since $\mathrm{C}_{\mathrm{p}}$ is constant, this may be written as

$$
\frac{d a}{d t}=\frac{2 k}{P}\left[B-L\left(C_{p}-C_{f}\right)\right]=\text { constant. }
$$

Then

$$
\frac{d a}{d h}=\frac{d a}{d t} \cdot \frac{1}{\frac{d h}{d t}}=\frac{d a}{d t} \cdot \frac{1}{v}=\text { constant. }
$$

Since $\frac{\mathrm{d} a}{\mathrm{dh}}=\mathrm{a}$ constant, " $a$ " varies linearly with column height. Integration from $a=0$ to $a=a_{0}$ and division by the column height gives $a_{a v}=\frac{a_{0}}{2}$

Relationships are now available for solving equation (14a) for specific element shapes. Three ideal shapes were chosen representing the usual shapes of fuel elements and the extremes in possible element shapes. These are:

(1) Thin-wall shapes. These are defined as shapes in which the thickness is very small compared to the other dimensions, and change in thickness during dissolution does not significantly change the other dimensions. The attack is considered to be one-dimensional. The shape is denoted by a shape factor, $\underline{p}=1$, where the shape factor is the reciprocal of the number of dimensions significantly attacked. Hollow shapes, as thinwall tubes, may be treated as thin flat plates bent so as to join two edges, giving results identical to those for flat plates.

(2) Circular or square rods. A limitation placed on these shapes is that their length is great enough compared to the other dimensions such that dissolution from the ends and the resulting change in length may be neglected with small error (a ratio of $c_{0} / a_{0}$ of about 5 is adequate). The attack is considered to be two-dinensional, or $\mathrm{p}=1 / 2$.

(3) Cubes and spheres. The dissolution in this case is threedimensional with attack in all dimensions taken into account, $\underline{p}=1 / 3$.

Equation (14a) may be written ir the following form to facilitate treachent of the specific ideal shapes:

$$
e(c)=\frac{F K k}{S} \int_{0}^{V}\left(\frac{a+b}{a}+\frac{I}{c}\right) d V
$$


IDO-14452

Page 14

where

$$
\theta(C)=\frac{2\left(C_{p}-C_{f}\right)}{\bar{B}-L\left(C_{p}-C_{f}\right)}
$$

3.3 Treatment of Specific Ideal Shapes

3.31 One-Dimensional Attack

The dimensions $\mathrm{b}$ and $\mathrm{c}$ are very large compared to $\mathrm{a}$,

where

$$
a=\text { thickness. }
$$

Then

$$
\begin{aligned}
& a+b \stackrel{\simeq}{=} \\
& \frac{a+b}{a b}+\frac{1}{c} \cong \frac{1}{a}+\frac{1}{c}
\end{aligned}
$$

Since

$$
\begin{aligned}
& c \gg a \\
& \frac{a+b}{a b}+\frac{1}{c} \cong \frac{1}{a}
\end{aligned}
$$

Substituting for the parenthetical group of equation (14b),

$$
\theta(C)=\frac{F K K}{S} \int_{0}^{V} \frac{d V}{a}
$$

But $\frac{a_{0}}{2}$ may be substituted as an average value of a, so equation (16) may be integrated to give

$$
\theta(C)=\frac{2 \mathrm{FKK}}{\mathrm{Sa}} \mathrm{V}
$$

The shape factor, $p$, may be incorporated here, where $p=1$.

$$
\theta(\mathrm{C})=\frac{2 F K k}{\mathrm{pSa}_{\mathrm{O}}} \mathrm{V}
$$

Equation (18) may be rearranged to give

$$
\frac{V}{a_{O}}=\frac{p}{2 F K}[\theta(C)]\left[\frac{S}{k}\right]
$$


Since the reactor concerned is a column, it is often more convenient to consider relationships in terms of column height instead of volume, and superficial liquid velocity (flow rate per unit column cross section) rather than volumetric flow rate.

$$
\begin{aligned}
& \dddot{V}=\frac{\pi D^{2}}{4} H \\
& S=\frac{\pi D^{2}}{4} S^{\prime}
\end{aligned}
$$

where

$$
\begin{aligned}
D & =\text { column diameter } \\
H & =\text { height of column (packed bed) } \\
S^{\prime} & =\text { superficial liquid velocity }
\end{aligned}
$$

Substitution for $V$ and $S$ in equation (19) gives

$$
\frac{H}{a_{O}}=\frac{p}{2 F K}[\theta(C)]\left[\frac{S^{\prime}}{k}\right]
$$

where all groups are dimensionless.

It may be desirable to utilize a group, $a_{0} / D$, as this will to some extent control packing characteristics and the surface area in the column. Equation (20) may also be written as

$$
\frac{H}{\bar{D}}=\frac{p}{2 F^{\prime} K}[\theta(c)]\left[\frac{a_{0}}{D}\right]\left[\frac{S^{\prime}}{k}\right]
$$

\subsection{Two-Dimensional Attack}

For the case of round or square rods the length dimension $c$ is much larger than $a$, and $a=b$ (= diameter for circular cross section).

$$
\frac{a+b}{a b}+\frac{1}{c}=\frac{2 a}{a^{2}}+\frac{1}{c} \cong \frac{2}{a}
$$

Substitution into equation (14b) yields

$$
\theta(c)=\frac{2 F K k}{S} \int_{0}^{V} \frac{d V}{a}
$$

Replacing a by $a_{0} / 2$ and integrating,

$$
\theta(c)=\frac{4 F K K}{a_{0} S} V
$$


IDO-14452

Page 16

Since the shape factor is

$$
p=1 / 2
$$

equation (22) may be written as

$$
\theta(\mathrm{C})=\frac{2 \mathrm{FKk}}{\mathrm{pSa_{0 }}} \mathrm{V}
$$

which is identical with equation (18) for thin wall shapes. Equation (19), (20), and (2l) also hold for round or square rods.

\subsection{Three-Dimensional Attack}

In the ideal case of spheres and cubes, $a=b=c(=$ diameter for spheres).

$$
\frac{a+b}{a b}+\frac{1}{c}=\frac{3}{a}
$$

Substituting into equation ( $14 b$ ), replacing a by $a_{0} / 2$, and integrating gives

$$
\theta(C)=\frac{6 F K K}{S a_{O}} \quad V
$$

Since $\mathrm{p}=1 / 3$, the above relationship becomes

$$
\theta(C)=\frac{2 F K k}{p S a_{0}} V
$$

This is identical to the previous cases.

\subsection{Summary of Relationships}

Equations were derived for three ideal shapes: thin-wall shapes which give essentially one-dimensional attack; shapes in which two dimensions are equal and the third is much greater, with two-dimensional ettack; and shapes in which all three dimensions are equal, giving three-dimersional attack.

All three cases can be represented by a single equation:

$$
\theta(C)=\frac{2 F K k}{p S a_{0}} V
$$

where

$$
\theta(c)=\frac{2\left(C_{p}-C_{f}\right)}{B-L\left(C_{p}-C_{f}\right)}
$$


The general equation may also be written as

$$
\frac{H}{a_{O}}=\frac{p}{2 F K}:[\theta(C)]\left[\frac{S^{\prime}}{k}\right]
$$

or

$$
\frac{H}{\bar{D}}=\frac{p}{2 F K}[\theta(c)]\left[\frac{a_{0}}{\bar{D}}\right]\left[\frac{S^{\prime}}{k}\right]
$$

The above equations are of the same form as those derived for nonmixing or tube-flow $(3)$; with only the value of $\theta(c)$, the function of concentration, being different. In the present case no integration was required to obtain the function and it is much simpler in form. Also, $\theta(C)$ is the same for all shapes with the shape effect evidenced only in the group $\frac{\mathrm{p}}{2 \mathrm{FK}} \cdot$. If an average value of the dimensions of metal elements had been taken directly, even the one simple integration used could have been avoided.

4. APPLICATION OF MODEL TO PILOT PLANT DATA

4.1 Method of Calculation

The procedure followed in calculating dissolution rate curves was essentially the same as that reported in the application of tube-flow relationships $(4)$. The data used were again primarily those reported by Boeglin and Buckham(1) for the mercury-catalyzed dissolution of 4 different shapes of extruded 25 aluminum in nitric acid in a 2-inch Pyrex continuous flooded dissolver. The shapes were round rods, tubes, flat plates, and flattened tubes.

The dissolver equation used, equation (20), was conveniently expressed in the form,

$$
\theta(\mathrm{C})=\frac{2 F K}{p}\left(\frac{\mathrm{H}}{a_{0}}\right)\left(\frac{k}{S^{\prime}}\right)
$$

In the dissolver operation the metal concentration in the dissolvent feed, $C_{f}$, was zero. In this situation, from equation (15),

$$
\theta(C)=\frac{2 C_{p}}{B-L C_{p}}
$$

Since there is no way of evaluating the gas evolution factor, $F$, from current information, it was assumed to be constant for the several shapes and conditions of operation and combined with the reaction velocity constant, $\mathrm{k}$, which was also assumed to be independent of shape. Thus, letting $\mathrm{k}^{\prime}=\mathrm{F}^{\prime} \mathrm{k}$, the dissolver equation may be written as 


$$
\theta(c)=\frac{2 K}{p}\left(\frac{H}{a_{0}}\right)\left(\frac{K^{1}}{S^{1}}\right)
$$

To facilitate computation, a plot of $\theta(C) / 2$ vs $C_{p}$ was prepared for $B=5.6 \mathrm{M}$ nitric acid and $L=3.88$ moles of acid consumed per mole of aluminum dissolved, the average conditions reported for the pilot plant runs(1). The curves are shown in Figure 1. For different values of $B$ a family of curves results very similar to that shown for the tube-flow dissolver. $(4)$

General curves for dissolution rate vs dissolvent flow rate; $i . e .$, proportional dissolution rate vs proportional flow rate, may be drawn in the same manner as demonstrated for tube flow (4), with the same conclusions from the shape of the curves. Nothing is gained by repeating the process here.

Dissolution rate vs flow rate data(I) were used to callculate $C_{p}$ values, $\theta(C)$ values were obtained from Figure 1 , and effective reaction velocity constants were calculated from equation (25). The values of the other required constants were obtained from Boeglin and Buckham(I), and are listed in Table 1 for the four shapes involved. The values for the round rods were used to calculate the velocity constants.

Table 1

Constants for the Dissolver Equation

Round Rods Tubes Flat Plates Flattened Tubes

$\begin{array}{lllll}\mathrm{p} & 1 / 2 & 1 & 1 & 1 \\ \mathrm{~K} & 0.453 & 0.071 & 0.411 & 0.244 \\ \mathrm{a} \text {, inches } & 0.25 & 0.028 & 0.0625 & 0.028 \\ \mathrm{H} * \text {, inches } & 108 & 108 & 108 & 108\end{array}$

*This is an average value; the height actually varied between 96 and 120 inches.

Solving equation (25) for $\mathrm{k}^{\prime}$ using the above constants for round rods gives

$$
k^{\prime}=0.002556 \theta(\mathrm{C}) S^{\prime}
$$

where $k^{\prime}$ and $S^{\prime}$ are necessarily in the same units.

There are disadvantages to calculating $\mathrm{k}$ i from the data rather than from a smooth curve draw through the data. These mainly involve the great sensitivity of $\theta(C)$ to $C_{p}$ at high values of $C_{p}$, as can be noted from Figure l. Thus, a very great effect results from experimental error in measured dissolution and flow rates and by the use of an average value for initial acid concentration. However, this approach was used for comparison with the method of using smoothed curves for the tube-flow 
FIGURE I

EVALUATION OF THE FUNCTION OF CONCENTRATION

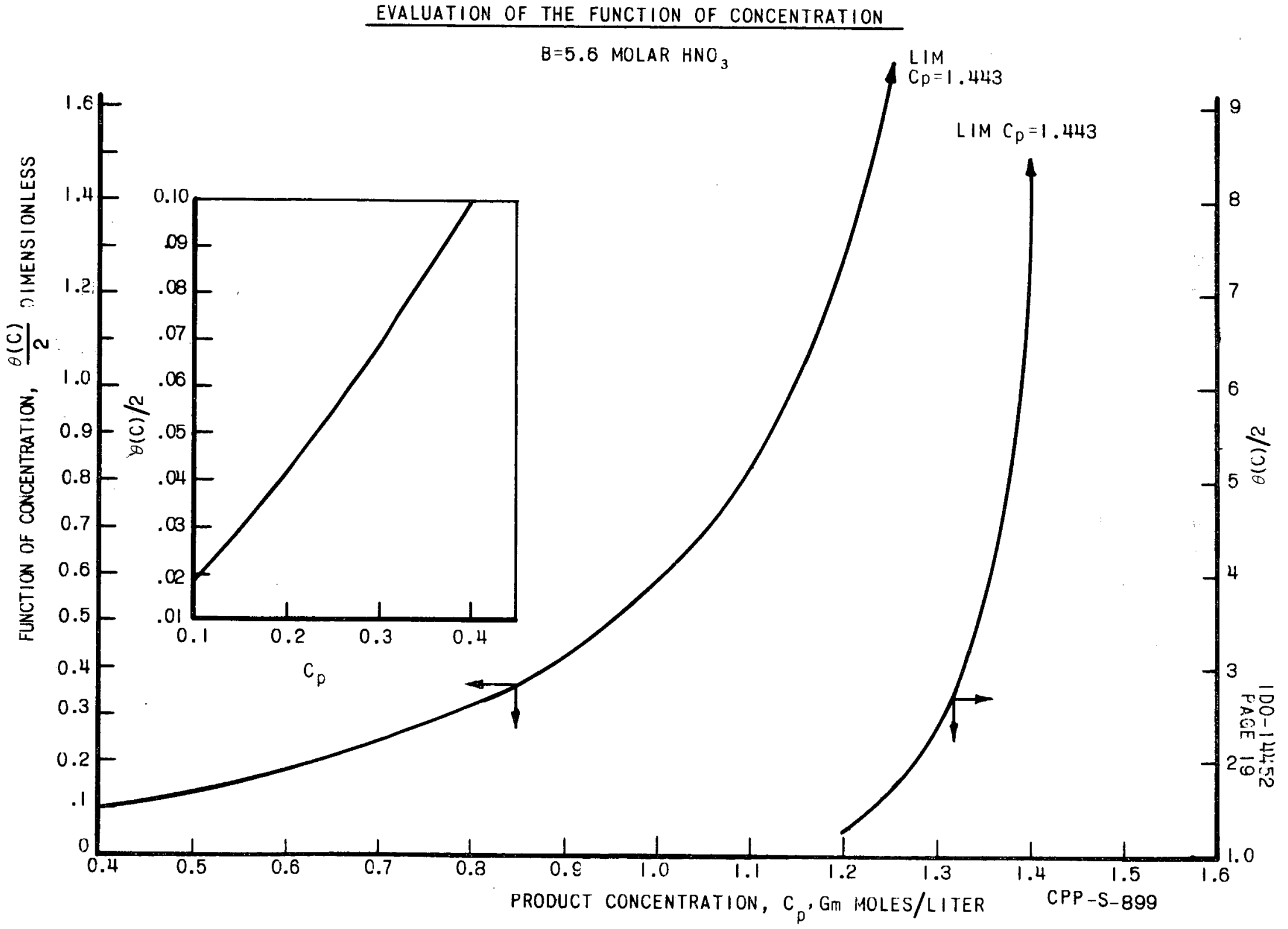


case ( 4 ), and to note whether the $k$ : value varied randomly or showed definite trends at a given catalyst concentration. In several cases the measured dissolution rates gave $C_{p}$ values greater than possible from the rate law for the initial acia concentration and the stoichiometric ratios used. This situation could result from the fact that an average value for the initial acid concentration was used to determine the $\theta(C)-C_{p}$ relationships. Actually, the initial concentration varied considerably. If the initial acid concentration was higher than the average value, $C_{p}$ could readily be higher than the calculated theoretical limit, while if the initial acid concentration was lower than the average, considerable error would result in the opposite direction. Also, dissolution near zero acid or in the acid deficient region would result in $c_{p}$ values higher than theoretical.

The results of the calculations are listed in Table 2 along with the selected average values of $\mathrm{k}^{\prime}$ which are plotted vs catalyst concentration in Figure 2. The values that appeared to be will were discarded before taking averages. No definite trends were noted in the $\mathrm{k}^{\mathrm{i}}$ values at a given catalyst concentration. This was encouraging, but the range of values was so great that no definite concilusions were drawn.

The curve for the velocity constants, Figure 2, is not critical, since the values for $k$ : taken from it are used principally to show the differences in the effect of slug shape upon dissolution rate at high and low catalyst concentrations. The use of the curve did not appear to warrant a statistical treatment of the data; two straight-line sections were drawn for convenience. The data for flat plates at the lowest catalyst concentration are more numerous and consistent than those for round rods, and give a k' value that falls nearly on the line. This fact, and indications from past experience that values for velocity constants level off at lower catalyst concentrations, suggest that the lower part of the curve be drawn with considerably less slope than indicated by the low catalyst data point.

Values for $\mathrm{k}^{\mathrm{i}}$ were taken from Figure 2 for each of the five pertinent catalyst concentrations. These values were used with the information in Table $I$ and equation (25) to calculate $\theta$ (C) for several liquid flow rates for each of the four shapes of elements. Figure 1 provided a corresponding value of $C_{p}$ for each case. Then, the dissolution rate was calculated as the product of the liquid flow rate and $C_{p}$ for the given situation. The results of these calculations are presented in Section 4.21.

Some data were made available by Buckham(2) for the effect of bed height on the rate of dissolution for extruded 25 aluminum round rods and tubes. Using a reaction velocity constant selected from Figure 2 and the physical constants from Table 1 , the dissolution rates were calculated from equation (25) for several bed heights. In this way, data from one experiment were used to predict the results of a completely different experiment for which measured rates were available. 
FI GURE 2

EFFECTIVE SPECIFIC REACTION VELOCITIES FOR ROUND ALUMINUM RODS

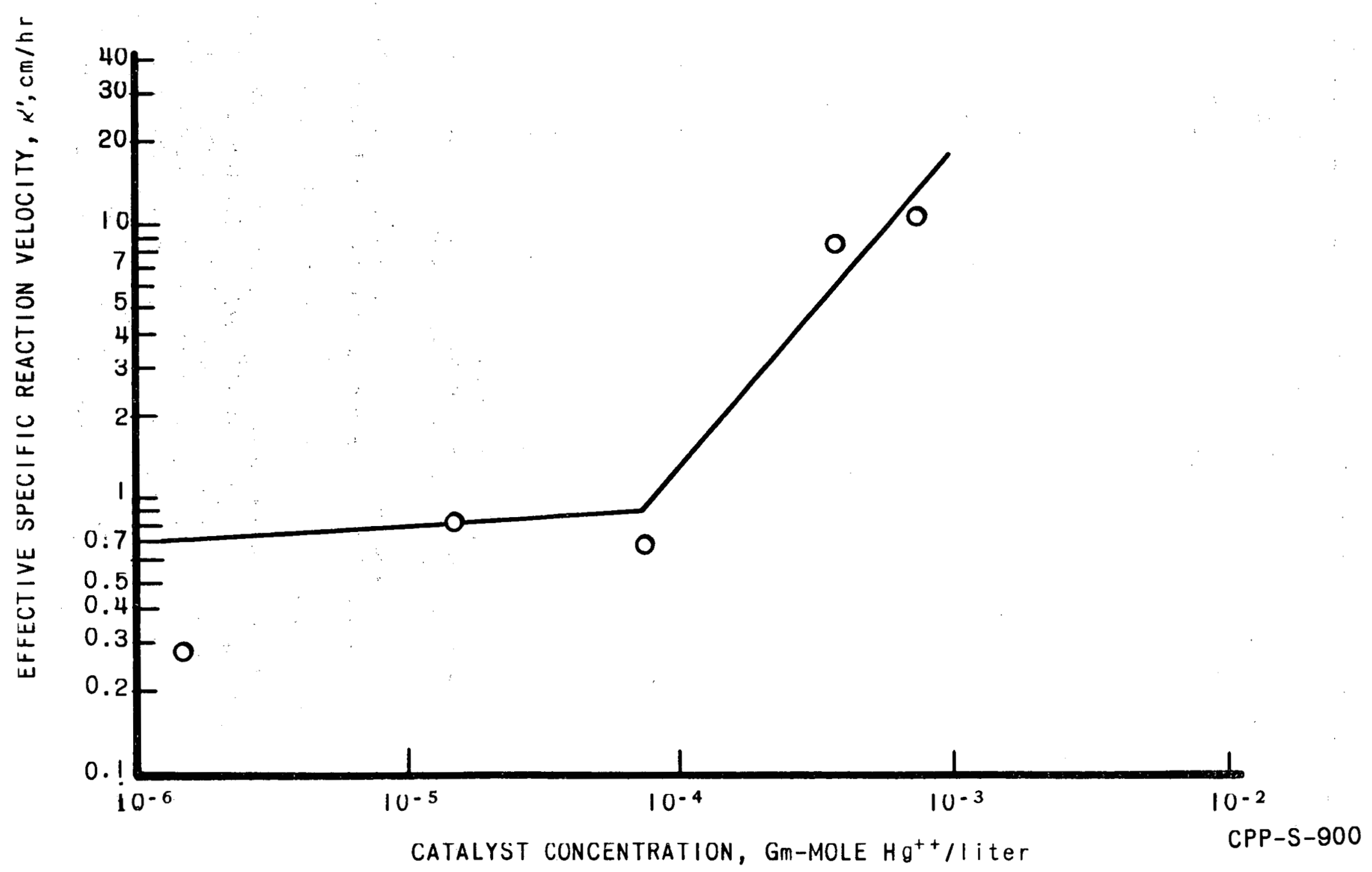


Table 2

Calculated Effective Specific Reaction Velocities for Round Rods

\begin{tabular}{|c|c|c|c|c|}
\hline $\begin{array}{l}\text { Catalyst Concentration } \\
\text { gm moles } \mathrm{Hg}^{++} / \text {liter }\end{array}$ & $\begin{array}{l}\text { Calculated } \mathrm{C}_{\mathrm{p}} \\
\mathrm{gm} \text { moles/liter }\end{array}$ & $\begin{array}{l}\mathrm{S}^{\prime} \\
\mathrm{cm} / \mathrm{hr} \\
\end{array}$ & $\begin{array}{c}\mathrm{k}^{\prime} \\
\mathrm{cm} / \mathrm{hr} \\
\end{array}$ & $\begin{array}{l}\mathrm{k}_{\mathrm{a}, \mathrm{v}}^{\prime} \\
\mathrm{cm} / \mathrm{hr} \\
\end{array}$ \\
\hline $7.5 \times 10^{-4}$ & $\begin{array}{l}1.387 \\
1.536 \\
1.404 \\
1.477 \\
1.279\end{array}$ & $\begin{array}{r}555 \\
591 \\
1105 \\
1145 \\
2485\end{array}$ & $\begin{array}{l}8.86 \\
-\cdots- \\
27.11 * \\
-12.7 \\
12.7\end{array}$ & 10.8 \\
\hline $3.75 \times 10^{-4}$ & $\begin{array}{l}1.366 \\
1.545 \\
1.584 \\
1.495 \\
1.321 \\
1.471 \\
0.511 \\
0.885\end{array}$ & $\begin{array}{r}669 \\
617 \\
626 \\
617 \\
1322 \\
1233 \\
2476 \\
2696\end{array}$ & $\begin{array}{c}7.61 \\
--- \\
--- \\
-- \\
9.39 \\
-- \\
-- \\
2.56 *\end{array}$ & 8.50 \\
\hline $7.5 \times 10^{-5}$ & $\begin{array}{l}1.256 \\
0.530 \\
0.719 \\
0.761 \\
0.177 \\
0.293\end{array}$ & $\begin{array}{r}643 \\
1251 \\
1251 \\
1322 \\
2493 \\
2652\end{array}$ & $\begin{array}{l}2.84 * \\
0.483 \\
0.826 \\
0.979 \\
0.227^{*} \\
0.440\end{array}$ & 0.68 \\
\hline $1.5 \times 10^{-5}$ & $\begin{array}{l}0.697 \\
0.708 \\
0.460\end{array}$ & $\begin{array}{r}634 \\
1260 \\
2634\end{array}$ & $\begin{array}{l}1 . .389 * \\
0.805 \\
0.828\end{array}$ & 0.82 \\
\hline $1.5 \times 10^{-6}$ & $\begin{array}{l}0.459 \\
0.397 \\
0.180\end{array}$ & $\begin{array}{r}582 \\
1287 \\
2661\end{array}$ & $\begin{array}{l}0.181 * \\
0.319 \\
0.248\end{array}$ & 0.28 \\
\hline
\end{tabular}

*These values are not included in averages

Note: The dissolution and flow rate data from which the above values were calculated were listed in an earlier report $(4)$.

The value of $\mathrm{k}^{\prime}$ used was $5.8 \mathrm{~cm} / \mathrm{hr}$ for $3.75 \times 10^{-4}$ molar catalyst. The dissolver equation for the two shapes involved simplified to:

$$
\text { rods: } \theta(\mathrm{C})=0.328 \mathrm{H}^{\prime} \quad \text { tubes: } \theta(\mathrm{c})=0.229 \mathrm{H}^{\prime}
$$

where $H^{\prime}$ is the column height in feet. The dissolvent flor rate was taken as an average from the data at $1375 \mathrm{~cm} / \mathrm{hr}$. The dissolution rate data had been normalized to this flow rate based on the empirical slope of 0.95 mentioned previously. This introduced another source of error, since at lower product concentrations the value of 0.95 does not appear to hold. The correction was not great, however, and the e pror introduced here tends to be small compared to that resulting from variations in the. initial acid concentration. The results of the calculations are given in Section 4.22 . 


\subsection{Prediction of Dissolution Rates}

4.21 Effect of Shape of Element

The results of the calculations described above for prediction of dissolution rates for four shapes of elements are listed in Table 3 . The calculated curves are shown in Figures 3 a-e for the five pertinent catalyst concentrations, along with the data(I) obtained for these situations in the pilot plant.

Tabse 3

Predicted Dissolution Rates fo: Four Shapes of Aluminum Elements

\begin{tabular}{|c|c|c|c|c|c|c|}
\hline \multirow[b]{2}{*}{$\begin{array}{l}\text { Catalyst Conc. } \\
\text { gm moles } \mathrm{Hg}^{++} / \text {liter }\end{array}$} & \multicolumn{2}{|c|}{$K^{\prime} \quad c r i l / 2 x$} & \multicolumn{4}{|c|}{ Dissolution Rate, gm moles/(hr) $\left(\mathrm{cm}^{2}\right)$} \\
\hline & $\begin{array}{l}\text { from } \\
\text { Fig.2 }\end{array}$ & $\begin{array}{c}S^{\prime} \\
\mathrm{cm} / \mathrm{hr} r \\
\end{array}$ & Rods & Plates & Tubes & $\begin{array}{l}\text { Flattened } \\
\text { Tubes }\end{array}$ \\
\hline $7.5 \times 10^{-4}$ & 12.7 & $\begin{array}{l}500 \\
1000 \\
1500 \\
2000 \\
3000\end{array}$ & $\begin{array}{l}0.704 \\
1.374 \\
1.960 \\
2.616 \\
3.750\end{array}$ & $\begin{array}{l}0.715 \\
1.403 \\
2.078 \\
2.732 \\
3.987\end{array}$ & $\begin{array}{l}0.696 \\
1.342 \\
1.947 \\
2.508 \\
3.528\end{array}$ & $\begin{array}{l}0.715 \\
1.410 \\
2.096 \\
2.764 \\
4.059\end{array}$ \\
\hline $3.75 \times 10^{-4}$ & 5.8 & $\begin{array}{r}500 \\
1000 \\
1500 \\
2000 \\
3000\end{array}$ & $\begin{array}{l}0.684 \\
1.297 \\
1.851 \\
2.350 \\
3.228\end{array}$ & $\begin{array}{l}0.700 \\
1.359 \\
1.969 \\
2.556 \\
3.645\end{array}$ & $\begin{array}{l}0.668 \\
1.240 \\
1.734 \\
2.172 \\
2.898\end{array}$ & $\begin{array}{l}0.704 \\
1.380 \\
2.022 \\
2.628 \\
3.771\end{array}$ \\
\hline $7.5 \times 10^{-5}$ & 0.90 & $\begin{array}{r}500 \\
1000 \\
1500 \\
2000 \\
3000\end{array}$ & $\begin{array}{l}0.528 \\
0.835 \\
1.028 \\
1.164 \\
1.320\end{array}$ & $\begin{array}{l}0.600 \\
1.026 \\
1.350 \\
1.594 \\
1.953\end{array}$ & $\begin{array}{l}0.472 \\
0.700 \\
0.833 \\
0.910 \\
1.035\end{array}$ & $\begin{array}{l}0.625 \\
1.101 \\
1.466 \\
1.770 \\
2.259\end{array}$ \\
\hline $1.5 \times 10^{-5}$ & 0.80 & $\begin{array}{r}500 \\
1000 \\
1500 \\
2000 \\
3000\end{array}$ & $\begin{array}{l}0.511 \\
0.795 \\
0.968 \\
1.076 \\
1.251\end{array}$ & $\begin{array}{l}0.587 \\
0.992 \\
1.287 \\
1.512 \\
1.815\end{array}$ & $\begin{array}{l}0.453 \\
0.655 \\
0.768 \\
0.858 \\
0.954\end{array}$ & $\begin{array}{l}0.616 \\
1.061 \\
1.409 \\
1.680 \\
2.079\end{array}$ \\
\hline $1.5 \times 10^{-6}$ & 0.67 & $\begin{array}{r}500 \\
1000 \\
1500 \\
2000 \\
3000\end{array}$ & $\begin{array}{l}0.484 \\
0.727 \\
0.869 \\
0.960 \\
1.095\end{array}$ & $\begin{array}{l}0.567 \\
0.935 \\
1.193 \\
1.380 \\
1.635\end{array}$ & $\begin{array}{l}0.422 \\
0.594 \\
0.675 \\
0.750 \\
0.825\end{array}$ & $\begin{array}{l}0.594 \\
1.011 \\
1.320 \\
1.556 \\
1.890\end{array}$ \\
\hline
\end{tabular}

4.22 Effect of Column Height

A summary of the calculated results and of the data for the effect of column height on dissolution rate is given in Table 4. The predicted curves are shown in Figure 4 along with the data(2) from the pilot plant. 


\section{FIGURE $3 \mathrm{a}$}

PREDICTED ALUMINUM DISSOLUTION RATE CURVES:-

$$
\left(\mathrm{Hg}^{++}\right)=7.5 \times 10^{-4} \mathrm{M}
$$

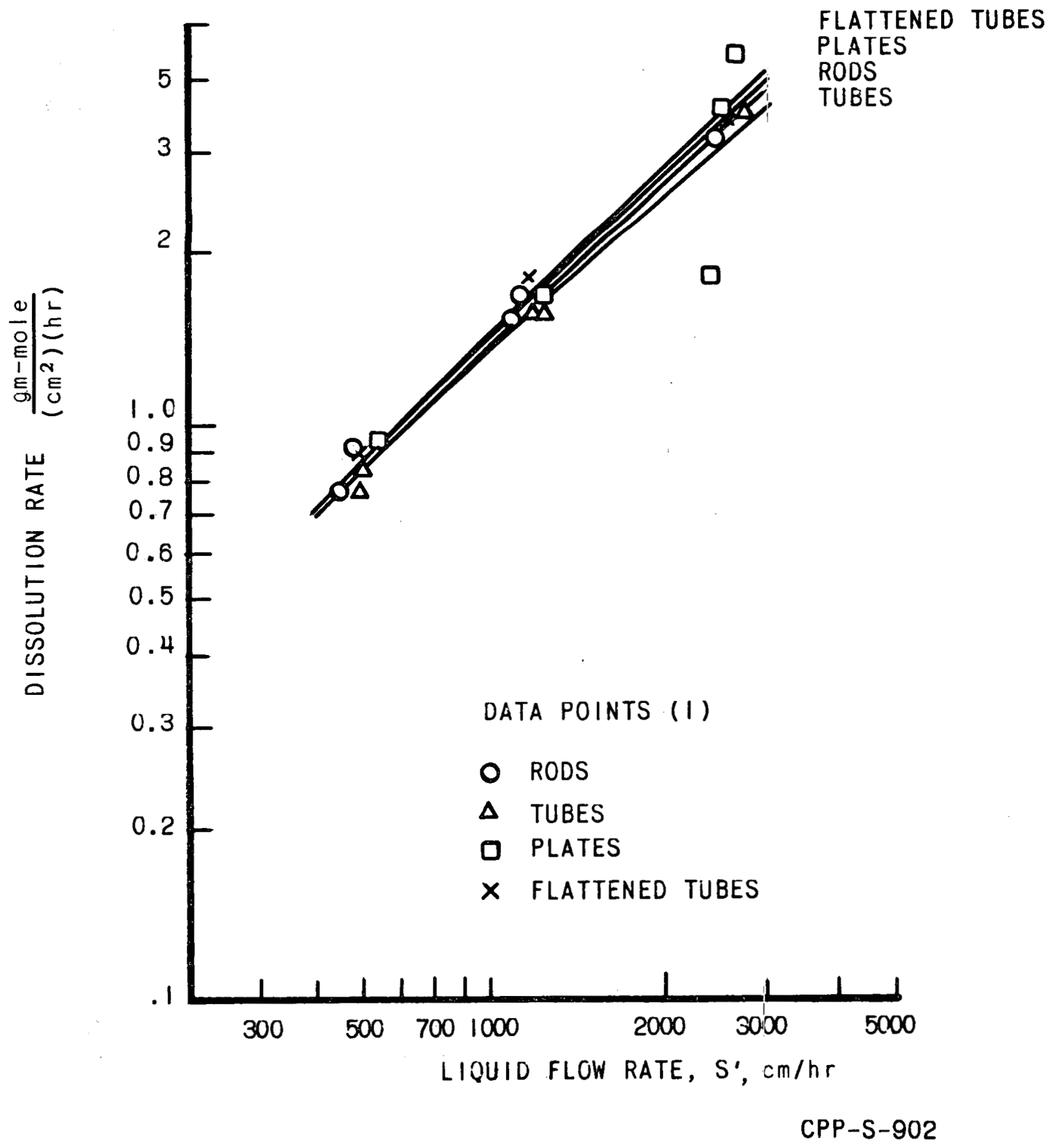


FIGURE 3b

PREDICTION ALUMINUM DTSSOLUTION RATE CURVES

$\left(\mathrm{Hg}^{++}\right)=3.75 \times 10^{-4} \mathrm{M}$

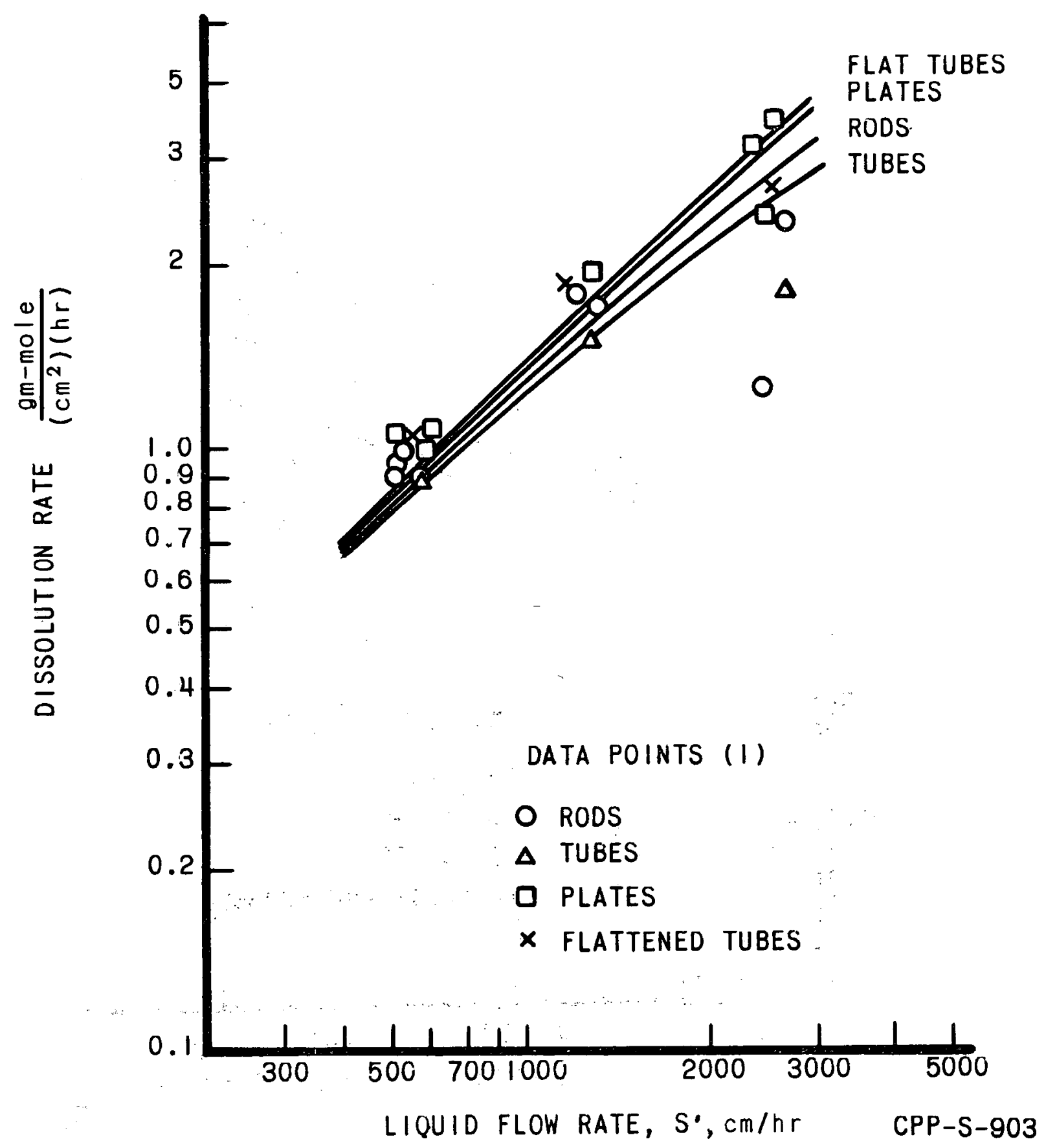


FIGURE $3 c$

PREDICTED ALUMINUM DISSOLUTION RATE CURVES

$$
\left(\mathrm{Hg}^{++}\right)=7.5 \times 10^{-5} \mathrm{M}
$$

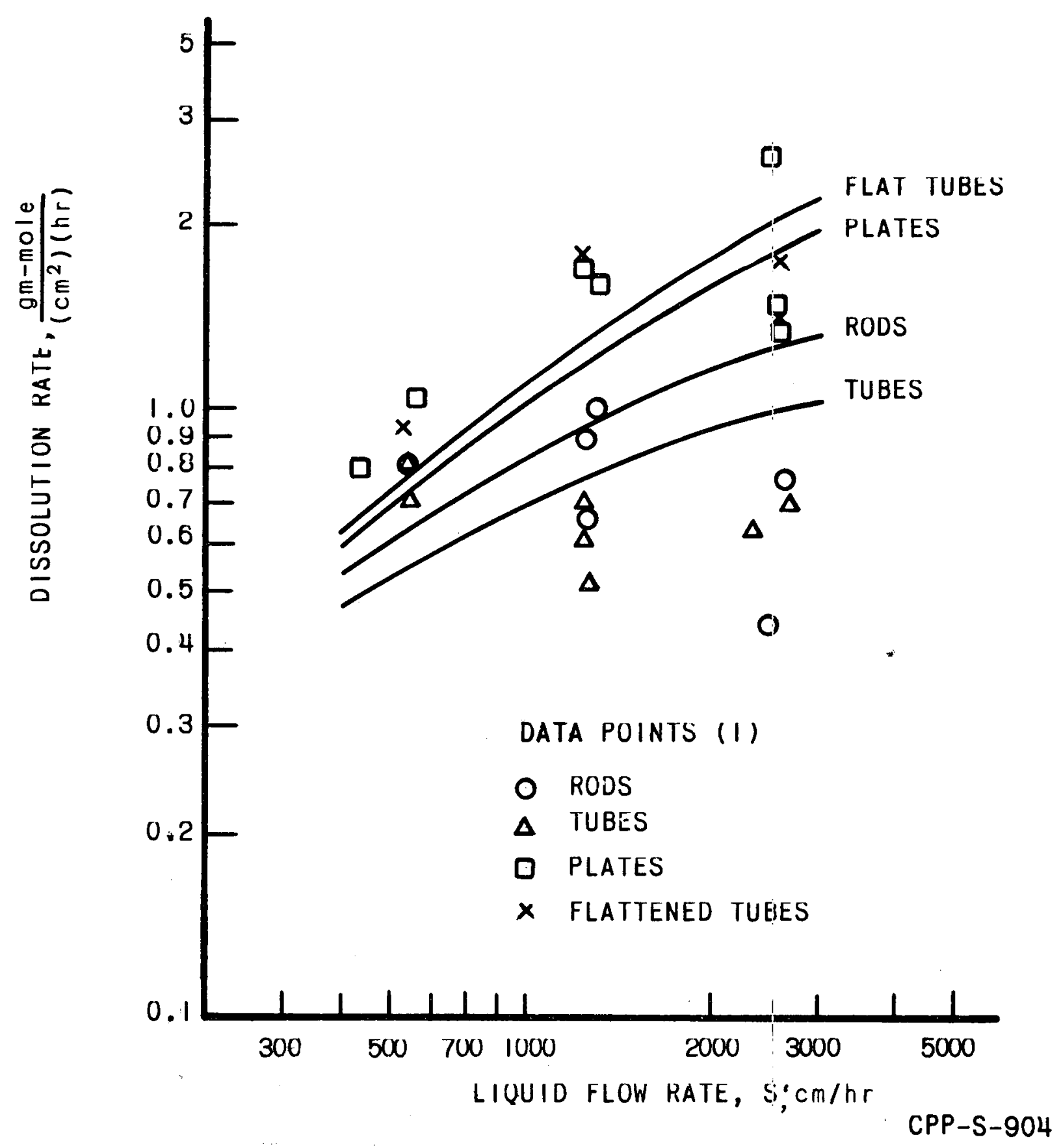


FIGURE 3d

PREDICTED ALUMINUM DISSOLUTION RATE CURVES

$$
\left(\mathrm{Hg}^{++}\right)=1.5 \times 10^{-5} \mathrm{M}
$$

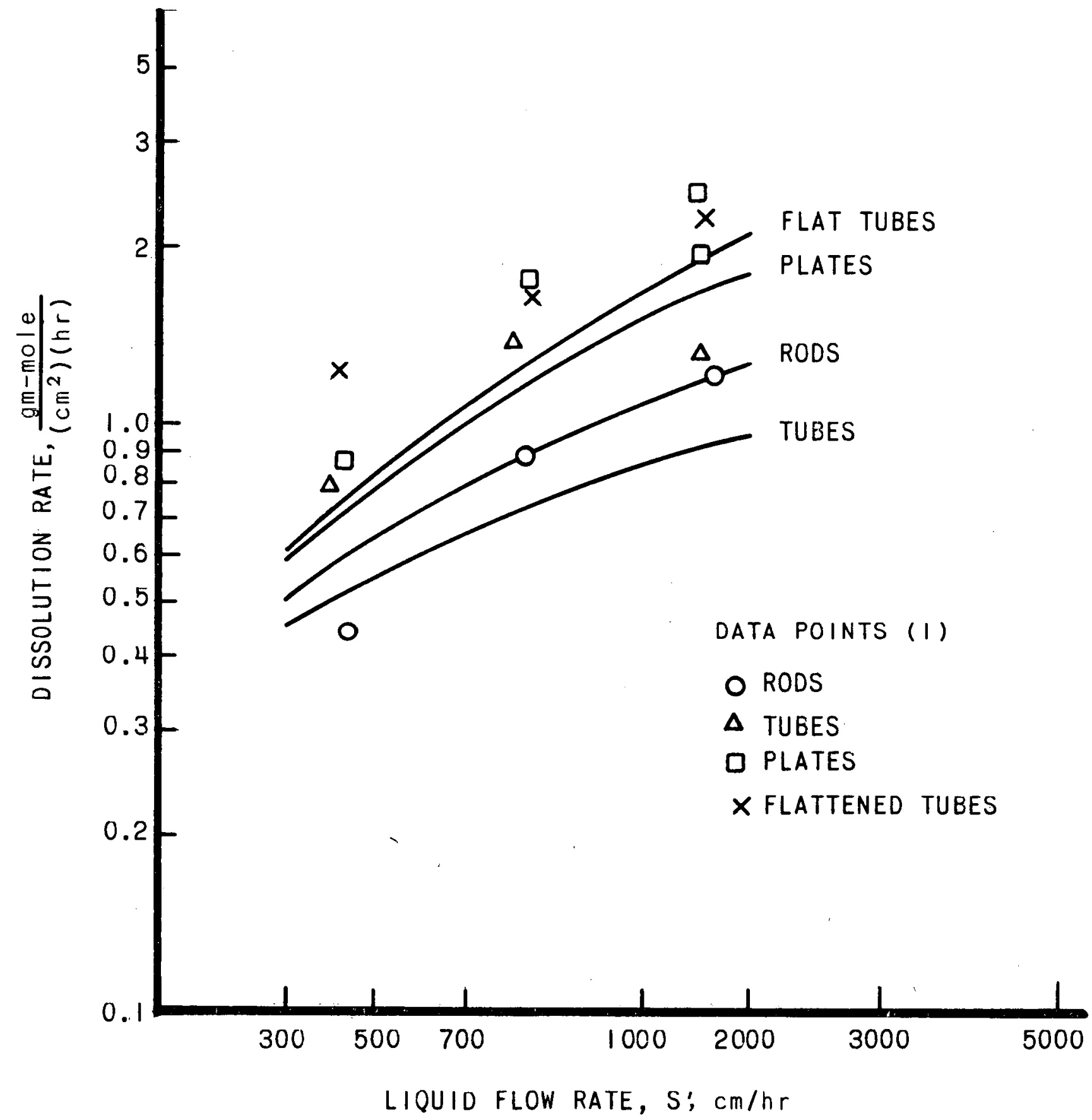


FIGURE $3 e$

PREDICTED ALUMINUM DISSOLUTION RATE CURVES

$$
\left(\mathrm{Hg}^{++}\right)=1.5 \times 10^{-6} \mathrm{M}
$$

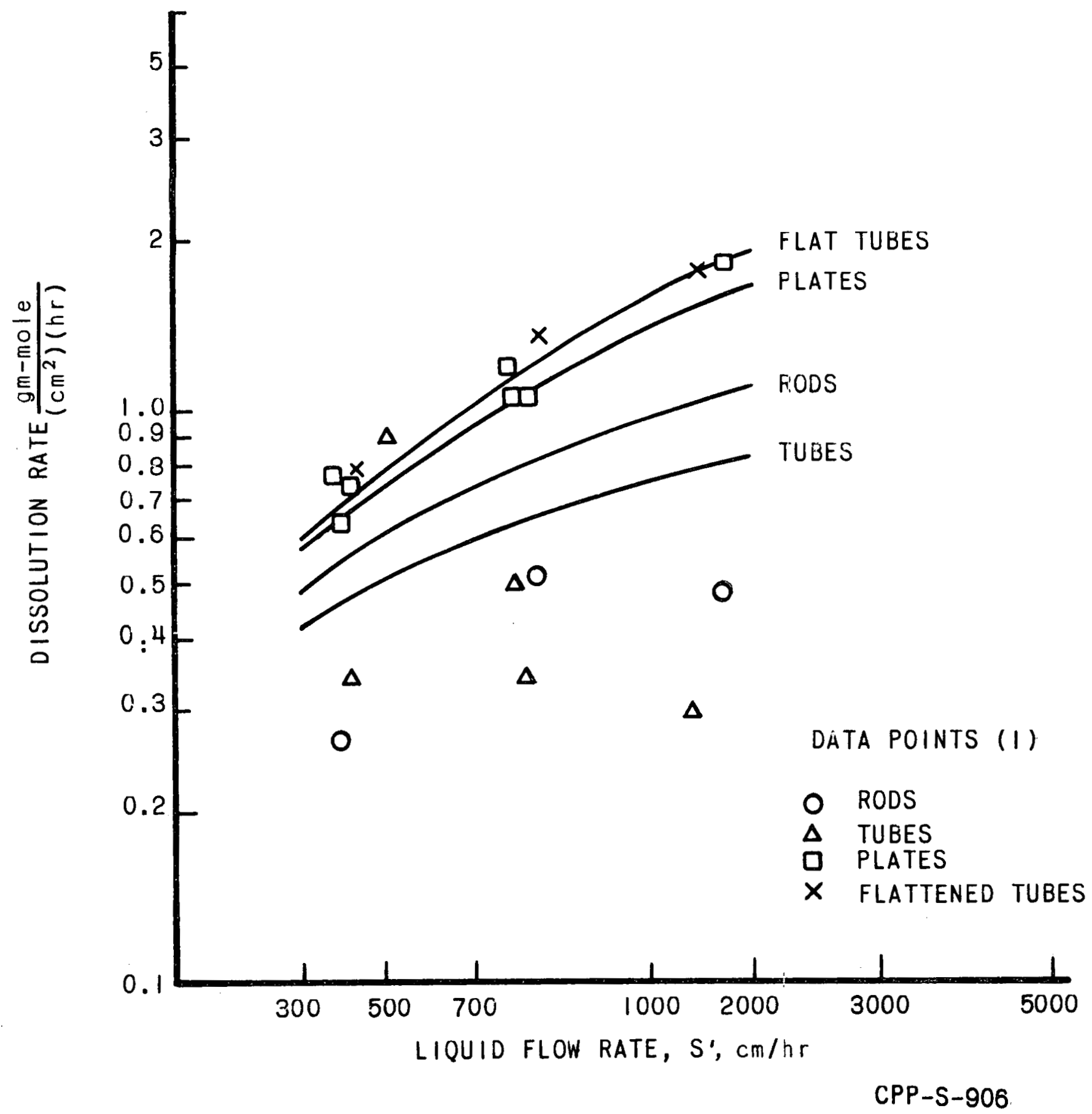


FIGURE 4

EFFECT OF BED HEIGHT ON DISSOLUTION RATE

$$
\left(\mathrm{Hg}^{++}\right)=3.75 \times 10^{-4} \mathrm{M}
$$

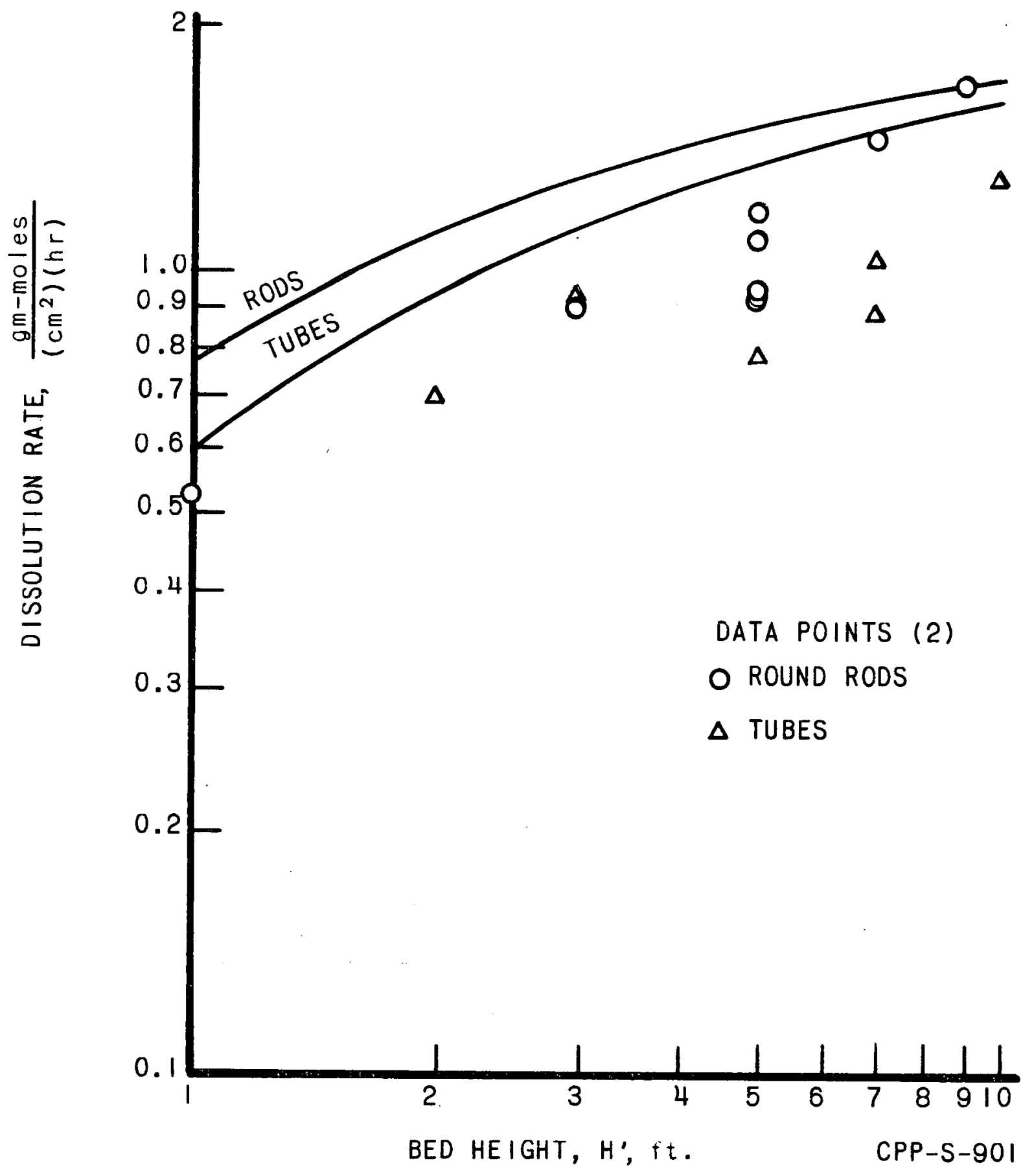


$1 D O-14452$

Page 30

Table 4

Effect of Bed Height on Dissolution Rate

\begin{tabular}{|c|c|c|c|c|}
\hline \multirow{2}{*}{$\begin{array}{c}\mathrm{H}^{\prime} \\
\text { Feet } \\
\end{array}$} & \multicolumn{2}{|c|}{$\begin{array}{l}\text { Calculated Rate } \\
\mathrm{gm} \text { moles } /\left(\mathrm{cm}^{2}\right)(\mathrm{hr})\end{array}$} & \multicolumn{2}{|c|}{$\begin{array}{c}\text { Measured Rate } \\
\mathrm{gm} \text { moles } /\left(\mathrm{cm}^{2}\right)(\mathrm{hr}) \\
\end{array}$} \\
\hline & Rods & Tubes & Rods & Tubes \\
\hline 1 & 0.770 & 0.598 & 0.524 & \\
\hline 2 & 1.110 & 0.928 & & 0.697 \\
\hline 3 & & & 0.906 & 0.925 \\
\hline 4 & $1.42^{2}$ & 1.271 & & \\
\hline 5 & & & $\begin{array}{l}1.183 \\
0.939 \\
1.094 \\
0.933\end{array}$ & 0.784 \\
\hline 6 & 1.570 & 1.441 & & \\
\hline 7 & & & 1.457 & $\begin{array}{l}1.029 \\
0.886\end{array}$ \\
\hline 8 & 1.660 & 1.547 & & \\
\hline 10 & 1.715 & 1.618 & 1.715 & 1.317 \\
\hline
\end{tabular}

5. DISCUSSION

The dissolution rate curves are very similar to those for the tubeflow case (4). The major difference appears to be in the more even separation of the curves for the four shapes. While the rods and tubes give rates below those for plates and ilattened tubes, the two groups are not so distinctly separated as for the former case. However, the general conclusions reached by Boeglin and Ruckham(1) from analysis of their data still appear to be fitted fairly well by the trends in the calculated rates. These are: (I) at the higher catalyst concentrations, the shape effect is unimportant and the rates can be expressel as a single line with a slope of 0.95 ; i.e.,

$$
R^{\prime}{ }^{\prime}=Q\left(S^{\prime}\right)^{0.95}
$$

and, (2) at the lower catalyst concentrations the plates and flattened tubes dissolve up to about $2-1 / 2$ times as fast as the round rods and tubes. Here, as in the case of nonmixing flow, a lower value of the effective reaction velocity constant for rods and tubes than for plates and flattened tubes would better match the data at the lowest catalyst concentration. This might conceivably be tied in with circulation patterns of the two phase (gas-liquid) flow in this region.

The sources of error involved which were discussed in the tube-flow assumption(4) generally apply here. In view of the assumptions involved, the variations in initial acid concentrations for the individual pilot plant runs and the experimental errors, the trends in dissolution rates with dissolvent flow rate, shape of fuel element, and column geometry are indicated quite well. 
It appears that the tank-flow or complete mixing assumption predicts the trends nearly as well as the nonmixing assumption. Since the tankflow equations, because of the simpler form of the function of concentration, $\theta(\mathrm{C})$, are considerably easier to use, the tank-flow model has much to recommend it. If the turbulence due to gas evolution could be eliminated, the tube-flow model would appear to be a more appropriate representation of the flow situation.

The dissolver equation has been shown to have the same form for both flow cases and for other assumed rate laws $(4)$, with the differences all appearing in the value of $\theta(C)$. Thus, the dissolver equation may be said to be general for the performance of a continuous flooded dissolver in which the metal elements form a bed of uniform packing characteristics. Until further knowledge of the factors involved is generated, the packing factor and element dimensions must be measured for the specific case in question, and an effective reaction velocity constant must be determined from operation of a continuous column. To become a directly useful tool in process design for a given dissolution, the reaction kinetics must be better defined and the effect of flow patterns better understood. 
6. NOMENCLATURE

a Smallest length dimension of metal element in column

a Smallest length dimension of initial (undissolved) element

B Initial nitric acid concentration in dissolvent feed

b Length dimension of metal element

$b_{0}$ Length dimension of initial element

C Metal concentration in dissolvent feed

$C_{p}$ Metal concentration in product

c Greatest length dimension of metal element in column

$c_{0}$ Greatest length dimension of initial element

D column diameter

d. diameter of metal element

e Shape factor of element for calculation of volume or area

F Gas evolution factor, dimensionless

[H] Hydrogen ion concentration

$\mathrm{H}$ Height of bed of elements in column

H' Height of bed of elements in feet

K Pa,cking factor, or l-void fraction, dimensionless

k Specific reaction velocity

$k^{\prime} \quad$ Effective specific reaction velocity, or Fk

I Stoichiometric ratio for dissolution of metal, dimensionless

M Mass feed rate of metal to column

m Mass of metal per unit volume or unit height of reactor

$n^{\prime} \quad$ Number of metal elements per unit volume of reactor

$\mathrm{p}$ Shape factor, the reciprocal of the number of dimensions significantly attacked in the dissolution, dimensionless 
Q Constant in empirical equation for dissolution rate

$r \quad$ Average reaction rate per unit volume of reactor

S Volumetric dissolvent flow rate

$S^{\prime} \quad$ Superficial dissolvent velocity

$s^{\prime}$ Surface area of metal per unit volume of column

sáv Average surface area per unit volume of column

s 1 Surface area of individual element in column

$t \quad$ Time

$\mathrm{V} \quad$ Volume of column

$v_{1}$ Volume of metal element in column

$\mathrm{v}$ Velocity of flow of metal elements in column

The only restriction on the units of the above quantities is that the equations in which the terms appear must be dimensionally consistent. 
IDO- 14452

Page 34

7. REFERENCES

(1) Boeglin, A.F., and Buckham, J.A., Effect of Geometrical Shape on the Continuous Dissolution of Aluminum in Mercury-Catalyzed Nitric Acid, IDO-14425, December 31, 1957

(2) Buckham, J.A., Unpublished data of C.F. Obenchain

(3) Erickson, E. E., Continuous Dissolver Theory, I. Development of General Relationships for a Tube-Flow Floode Dissolver, IDO-14450, November 24, 1958

(4) Erickson, E. E., Continuous Dissolver Theory, II. Application of Thbe-Flow Relationships to Data from a Two-Inch Continuous Flooded Dissolver, IDO-14451, January 14, 1959

(5) Stevenson, C. E., Quarterly Progress Report, Technical Branch, Idaho Chemical Processing Plant, IDO-14324, 1954 (Secret) 